iron-nickel alloys, and suggested correlations between the twinning and different morphologies observed and the martensite hardness. Venables has worked on thin films of stainless steel transformed by cold work, where stacking faults, regions of hexagonal $\varepsilon$-phase and regions of body-centred cubic $\alpha^{\prime}$-phase can be seen. Other papers in this session described extensions to the crystallographic theory (Wechsler and Otte) and etch-pit investigations of dislocations in the austenite (Reed and Greeson).

Thus, the subject of defects in crystals continues to expand at an ever-increasing rate, particularly under the stimulus of the development of experimental techniques permitting direct observation of dislocation lines, of which the dominant one is now the use of the electron microscope to examine thin metal films by transmission. With these high. resolution studies, our knowledge of the detailed behaviour of individual dislocations and other lattice defects is increasing rapidly, and the next ten years: will see a great extension in work of this kind. While possible differences in the behaviour of defects in thin films and bulk specimens must always be borne in mind, it is clear that much valuable information about the basic mechanisms controlling bulk mechanical properties will be obtained in this way. Such information must indeed play an essential part in the solution of the more difficult problems concerned with the development of theories about the bulk mechanical $\begin{array}{ll}\text { properties of practical interest. } & \text { B. A. BזLBY }\end{array}$

\title{
CO-ORDINATION CHEMISTRY
}

A SYMPOSIUM on Co-ordination Chemistry with an international attendance was held in Prague during September 5-8. It was organized by the Czechoslovak Chemical Society and by the Faculties of Inorganic Chemistry of the Charles University and the Technical University and sponsored by the Czechoslovak Academy of Sciences.

The introductory paper by Prof. A. A. Grinberg (Leningrad) consisted of a survey of the development of co-ordination chemistry in the past decade and a generel review of the present position of the subject. This was followed by a general discussion of the applications of polarography by Dr. A. A. Vlček, a member of the Polarographic Institute at Prague. Dr. Vleek emphasized, in particular, the importance of searching for new complexing agents which would permit the electro-deposition of a wider range of metals than can at present be utilized in this way.

The other scientific meetings were grouped into three sections, concerned with modern preparative methods, with the physico-chemical properties and structure of complexes, and with direct methods of structure determination, respectively. Prof. S. Herzog opened the first main session with a paper on the properties of low-valency co-ordination compounds of metals with dipyridyl and phenanthroline. He described some remarkable substances, for example, zero-valent tris-dipyridyl derivatives of titanium, scandium and even niobium. The existence of such compounds and of magnesium and lithium dipyridyl derivatives was shown to raise a number of important problems in valency theory which were discussed in some detail. Whother these compounds are to be regarded as truo low-valency compounds of the metals, or as complexes of the dipyridyl anion radical, was the interesting question which emerged in discussion.

Among the contributed papers one can mention only a few. Prof. E. O. Fischer (Munich) described the preparation of a variety of mixed diene-carbonyl complexes of zero-valent metals and discussed some very remarkable rearrangements which they undergo. Prof. I. I. Chernaev (Moscow) described his extensive work on the nitro complexes of tetravalent platinum. Dr. K. Isslieb (Jena) described a large number of novel complexes of transition-metal ions with primary and secondary phosphines. Complexes of tri- and tetra-dentate arsenic ligands were discussed by a group from Oxford.
The section on physico-chemical methods was opened by Dr. L. E. Orgel (Cambridge), who gave an elementary account of the principles of ligand-field theory and of modern methods of determining the spatial distribution of unpaired $d$ electrons in transition-metal complexes. This was followed by an entertaining paper by Dr. L. G. Sillen (Stockholm). who summarized the extensive research of his school on the varied hydrolysis reactions of metal ions in aqueous solution.

Madame B. Jezowska-Trzebiatowska (Warsaw) described the use of optical and magnetic measurements in discussing the electronic structure of a variety of co-ordination complexes. The trans effect in a variety of complexes of divalent platinum, trivalent cobalt and divalent copper was treated in a series of papers.

A further group of papers dealt with applications of polarographic methods. Prof. K. B. Yatsimirskii (Kiev) described ingenious methods of using the catalytic polarographic currents to study complexes in solution; Miss D. Wagnerova (Prague) discussed the polarographic reduction of ruthenium nitrosyls, and Dr. E. Fischerova described similar work on trivalent chromium complexes.

The final section was opened by Prof. Porai Koshitz (Moscow), who gave a concise summary of the present state of our knowledge of the environments of metal ions in co-ordination compounds as determined by direct $\mathbf{X}$-ray studies. There followed a series of papers describing structural studies on individual compounds. One may mention in par. ticular papers on the periodate of trivalent copper, on the dipyridine adduct of the dimer of copper acetate, and on $\left(\mathrm{NH}_{2} \cdot \mathrm{CH}_{2} \cdot \mathrm{CH}_{2} \cdot \mathrm{NH}_{2}\right) \mathrm{CuBr}_{2}$. Another paper in this series by Czech crystallographers discussed the mechanism of the substitution reactions of cupric compounds.

The meeting as a whole provided an excellent opportunity for the exchange of ideas and information between scientists of all countries. For those from the Western countries it was a particular pleasure to meet and talk with their opposite numbers from Eastern Europe. Apart from tho main scientific business of the meeting, foreign delegates were most hospitably entertained-a tour of the medieval city of Prague, an excursion to neighbouring points of interest and the various social activities in the evenings were greatly enjoyed by those present. I. E. Orasr. 